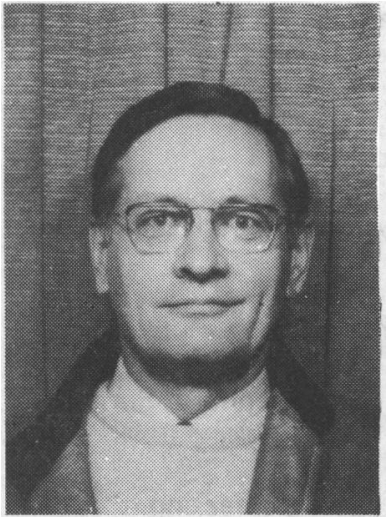

P. J. Bedford

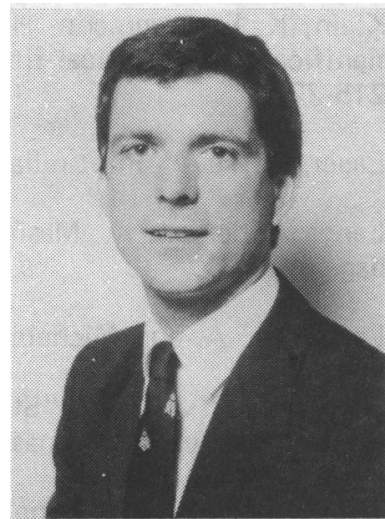

D. C. Macauley

\title{
ATTENDANCES AT A CASUALTY DEPARTMENT FOR SPORT RELATED INJURIES
}

\author{
P. J. BEDFORD, BM, BCh and D. C. MACAULEY, MB, BCh, BAO, DRCOG
}

Royal Devon and Exeter Hospital (Wonford), Barrack Road, Exeter \begin{abstract}
a specialist sports injury service.
\section{INTRODUCTION}

A prospective analysis of casualty attendances was undertaken in the Accident and Emergency Department of the Royal Devon and Exeter Hospital (Wonford), a District General Hospital with a catchment area of 253,579 hectares (approximately 1,000 square miles of Devonshire) and population of 294,300 . The study was made in order to assess the nature and number of sports injury consultations, and to plan improvements in the existing system. As each patient attended, details were recorded of age, sex, time of arrival, the cause of injury, treatment and discharge. Further information was available from the casualty case notes. This method of recording commenced two weeks prior to the official survey and required little variation from the usual procedure.
\end{abstract}

ABSTRACT

In a prospective study over a period of 5 months (July-November, 1982), 506 patients were treated at a Distric General Hospital for a sports related injury. All the patients were seen initially in the Casualty Department and the majority of attendances $(58 \%)$ were due to injuries caused by the two principal contact sports - Association and Rugby football. There were 294 patients (58\%) aged 21 or less and $45(9 \%)$ were aged 15 . The study was intended to provide a summary that would quantify the local problem and assess both the efficacy of the existing system and the need for

Out of a total number of 14,117 new patient attendances during the period, $506(3.6 \%)$ were attributed to sport. Other analyses of casualty statistics have demonstrated similar proportions, (Compton and Tubbs, 1977) 7\% of 40,169 new patients; (Sleet and Donnan, 1979) $5.4 \%$ of 8,000 new patients; and (Sperryn and Williams,
1975) $4 \%$, number unspecified.

$84 \%$ of patients were male and although there was some minimal monthly variation in the relative percentages of male and female, the results are similar to previous analyses (Compton and Tubbs, 1977; Devereaux and Lachmann, 1983).

\section{THE SPORTS}

Association and Rugby Union football contributed the greatest number of injuries - respectively $34 \%$ and $24 \%$ of the total. The proportions are broadly similar to other studies in accident and emergency and sports injury clinics. (Adams, 1980; Compton and Tubbs, 1977; Devereaux and Lachmann, 1983; Galasko et al, 1982; Mowat, 1981; Newman et al, 1969).

Weightman and Browne (1974) assessed the risks of injury in Association football as $\mathbf{3 6 . 5}$ for 10,000 man hours play and 30.5 for Rugby and also showed that although one would expect injury every 5 seasons in Rugby and every 2-5 seasons in Association football, 


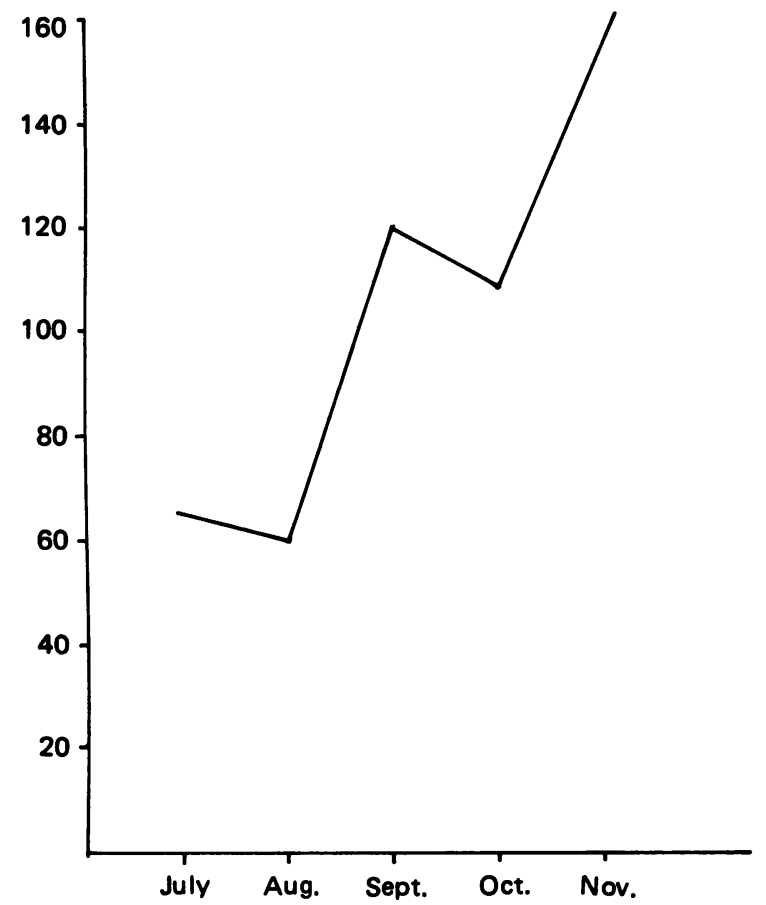

Fig. 1: Total attendances of sports related injuries per month, Royal Devon and Exeter Hospital, summer and autumn 1982.

the Rugby injuries were more serious - $130 \%$ of soccer injuries and $50 \%$ of Rugby injuries required hospital treatment). Muckle and Shepherdson (1975) found the injury rate per 100 participants as 4.9 in Rugby (equal to skiing) and Association football as 3.2.

Horse riding contributed the third highest number of injuries (9\% of the total), approximately one half (22) of whom were teenage girls. This is markedly different from other published data and presumably reflects our semi-rural catchment area. As in other parts of the country, there has been a huge increase in distance running. We saw only two injuries related to running. This clearly does not reflect the number of active athletes, nor does it correspond with figures from other sources. However, most endurance type sports injuries are chronic overuse injuries and would be more likely to present to a specialist sports injury clinic than a casualty department. In 1980 Adams reported $14.5 \%$ of attendances at the sports injury clinic were from track and field athletes compared with 1.3\% of sports attendances at casualty. Devereaux and Lachmann (1983) in their sports injury clinic demonstrated $19.8 \%$ of their injuries to be related to running. There has been interest and alarm at the incidence of sudden death in sport but we had no fatalities during the period of this study.
Percentage of total injuries related to individual sports

$\begin{array}{lc}\text { Soccer } & 34.0 \% \\ \text { Rugby } & 24.0 \% \\ \text { Horse riding } & 8.8 \% \\ \text { Cricket } & 4.75 \% \\ \text { Hockey } & 2.5 \% \\ \text { Basketball } & \\ \text { Volleyball } & 7.3 \% \\ \text { Netball } & \\ \text { Tennis } & \\ \begin{array}{l}\text { Squash } \\ \text { Badminton } \\ \text { Motorcycle sports }\end{array} & 3.5 \% \\ \begin{array}{l}\text { Athletics } \\ \text { Cross country }\end{array} & 3.75 \% \\ \text { Jogging } & 0.4 \% \\ \text { Miscellaneous } & 9.0 \%\end{array}$

\section{Anatomical Distribution}

The anatomical distribution of injuries remained relatively constant throughout the autumn, and roughly similar to those reported by Galasko et al (1982), Newman et al (1969) and Williams (1973), but different from Devereaux and Lachmann (1983). Upper limb injuries affected mostly the hand and although hand injuries are not life threatening, they are potentially disabling in terms of loss of function and employment. It may be valuable to assess the long term progress in terms of functional disability.

Lower limb injuries affected predominantly the ankle (15\% of total) and the knee ( $9 \%$ of total). Devereaux and Lachmann found knee injuries to be 23.2\% of their total.

In spite of widespread publicity attributed to neck injuries in Rugby football and other sports, we had no reported cases. Neck injuries are often seriously disabling, sometimes fatal (Silver, 1984). Perhaps we were lucky.

Percentage of total injuries related to anatomical site

$\begin{array}{lr}\text { Head and neck } & 5.7 \\ \text { Nose } & 2.7 \\ \text { Face } & 6.7 \\ \text { Shoulder } & 6.9 \\ \text { Arm } & 8.4 \\ \text { Wrist } & 4.9 \\ \text { Hand } & 16.4 \\ \text { Knee } & 9.2 \\ \text { Ankle } & 14.8 \\ \text { Foot } & 7.7 \\ \text { Combined others } & 9.3\end{array}$




\section{Age Distribution}

The majority (58\%) of injuries occurred in young males aged 21 or less but the distribution of injuries within this age group is interesting. There are few reported injuries until age ten, but a sharp increase with a peak at age fifteen in boys and at fourteen and fifteen in girls. For boys at age fifteen $66 \%$ of injuries were caused by the contact sports - $36 \%$ due to Rugby and $30 \%$ due to football. For girls, aged 15, horse riding provided the greatest number, though the sample sizes are particularly small.

When one compares these figures with the growth velocity curves (after Tanner et al, 1966) one may demonstrate this injury peak one year after the growth spurt. How does this relate to the aetiology of the injuries? Is the delay in incidence of injuries significant? Contact sports account for two thirds of the injuries; is this a reflection of increased participation or is there some other factor related to size and maturity?

Exertion or chronic overuse injuries do have different aetiological patterns in adolescents (Orava and Puranen, 1978; Williams, 1981) so it is conceivable that there are different factors at play in adolescent acute injuries. It is suggested that a) discrepancy of size in team sports may be a factor in injury and it has also been suggested that neuromuscular co-ordination lags behind simple physical growth; b) that school sport should be graded by physiological rather than chronological age.

Whatever the reason, there is a peak at the age of fifteen and this requires further investigation.
Time, Day and Month

Saturday and Sunday were predictably the days with the greatest number of attendances. Monday was high, Tuesday, Wednesday and Thursday approximately equal, with a drop on Friday.

The peak times of attendance were Saturday afternoon from two till six, $(58 / 11 \%$ of the total) and Sunday morning from nine until one, $140 / 8 \%$ of the total) which coincide with the periods of maximum community sport. But the total from these two periods (98) is still only $20 \%$ of all attendances. One may postulate, and a number of authors have suggested (Adams, 1980; Cyriax, 1975; Butler, 1980) that the rise on Monday mornings was as a result of weekend activities but there is a uniform distribution for the remainder of the week and this has particular relevance to the provision of a specialist sport injury service.

In terms of planning this service, it would, therefore, be appropriate to employ a sports orientated doctor to cover the period not only of maximum attendance, but also on a daily basis throughout the week. From the information available if a doctor were to be employed to cover the periods of maximum attendance ( 8 hours Saturday and 10 hours Sunday) that would still only be $40 \%$ of all attendances.

In terms of the social costs of sports injury 177/35\% attended during the standard working hours of nine to five, and depending on the severity of the injury and waiting times at the hospital and subsequent rest at home, this represents a significant loss of working time.

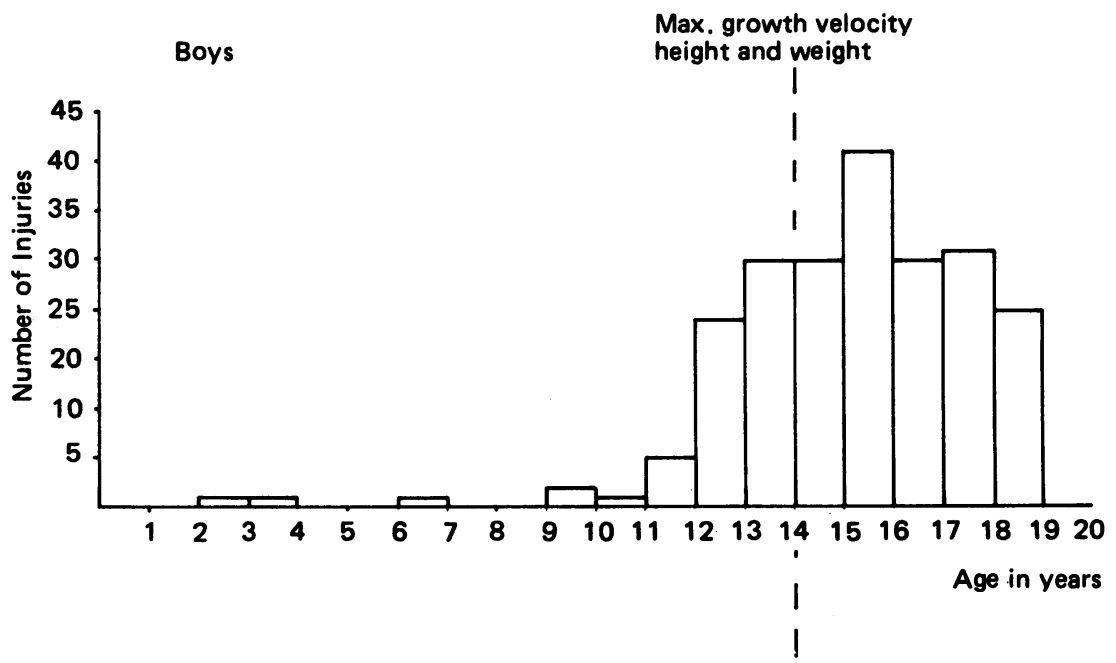

Fig. 2: Age distribution of injuries in younger males. 


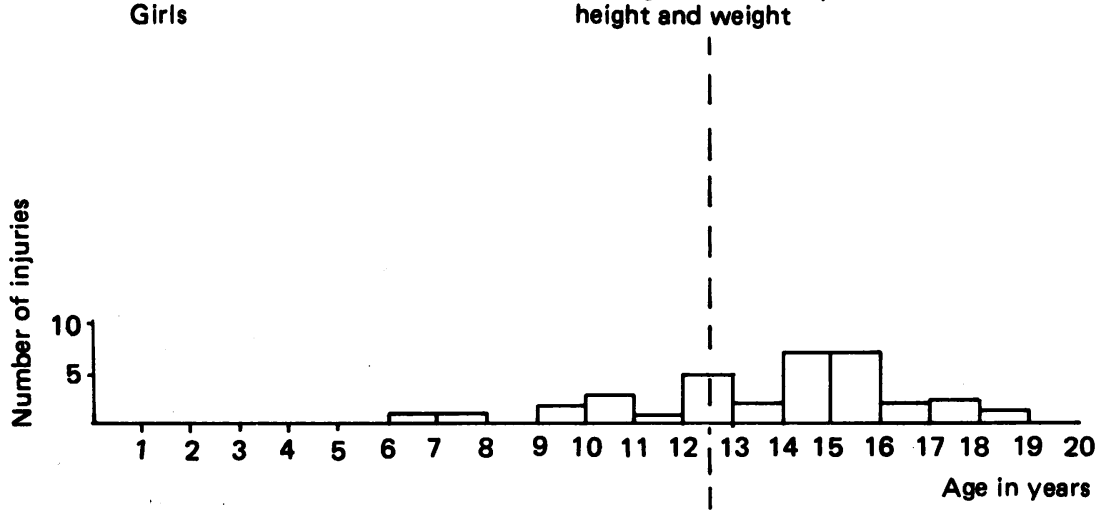

Fig. 3: Age distribution of injuries in younger females.

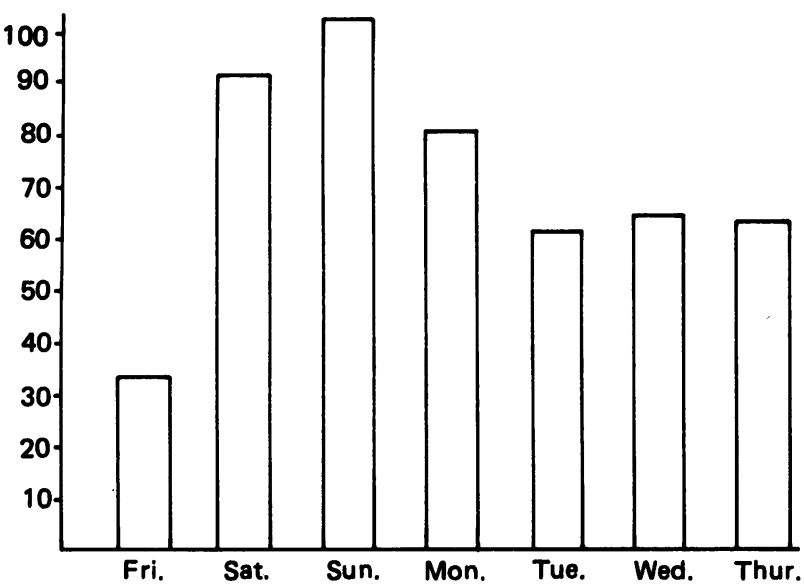

Fig. 4: Number of attendances on each day of the week.

\section{Month of the Year}

Although we have only five months' statistics, a pattern is identifiable. The general increase in Rugby and Association football and decrease in cricket injuries was predictable. However, there was a marked rise in all injuries in September and in particular a dramatic increase in Rugby injuries in November. The first observation fits nicely with the postulated theories in the aetiology of sports injury; that the rise in September is due to the return to active sport after the summer recess, and resuming contact sports before full return to fitness.

The peak of Rugby injuries in November is more difficult to interpret. Davies and Gibson (1978) reported that $60 \%$ of Rugby injuries occur in soft or muddy

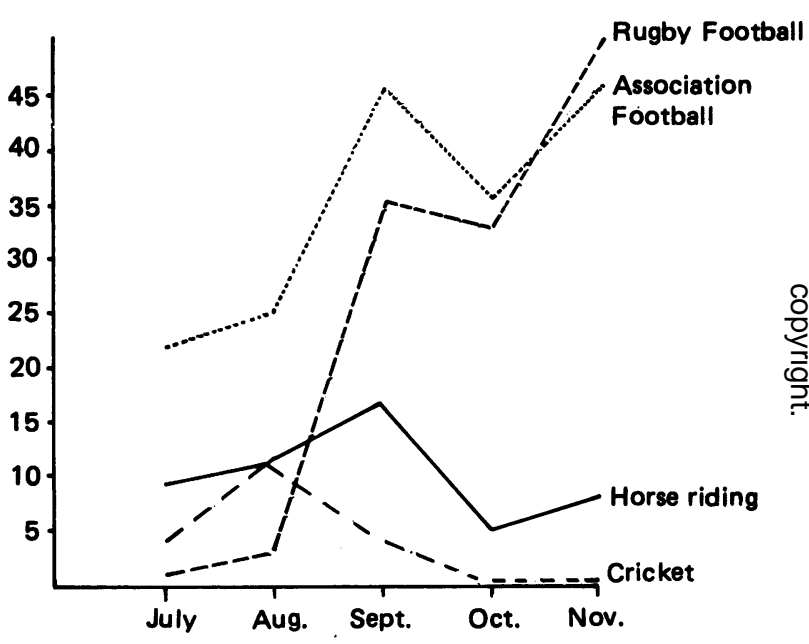

Fig. 5: Attendances related to sport and month.

conditions; and that head and neck injuries were significantly more common in wet conditions. It was particularly wet in October and November in the Exeter District with $33 \%$ more rainfall than average in October and $63 \%$ more in November (Personal communication). This may be proposed as an underlying factor for an abnormal pattern of injury. It would be necessary to have a profile of the monthly pattern of injuries throughout the year and for a number of years to establish this as a recurring feature; and it may also help to correlate the type of injury with seasonal and environmental conditions.

Sports Injury Clinics?

Is there a need for a sports injury clinic? From the figures available (of new patient attendances) and their distribution, there are not sufficient numbers to warrant 
a special clinic, and it would not be possible to provide expertise, on the spot, to cover all attendances. However, this represents the service available in practice and not necessarily the service required.

Since the survey we have now developed a two tier system in Exeter. Acute sports injuries attend casualty where they are seen by a duty medical officer and treated as required. In addition, the soft tissue clinics on Thursday and Monday mornings will accept sports injuries referred either from casualty or by General Practitioners.

There is rapid easy access to physiotherapy and specialist orthopaedic assessment from both departments.

\section{CONCLUSION}

The data presented in this study are limited by the duration of the study, the relatively small numbers available and is biased in studying autumn and winter patterns.
It is an analysis of only one aspect of the sports injury, the acute injury presenting at the Accident and Emergency Department. Many with minor injuries will attend their General Practitioner and chronic injuries may attend a specialist clinic. However, a number of important points have emerged.

1. The widespread distribution of attendances in respect of time and day makes it desirable that a specialist service should be available on a daily basis. However, the numbers involved do not justify the provision of such a specialist service and the present system appears to offer a reasonable compromise.

2. Contact sports provided the bulk of attendances in spite of the recent upsurge of interest in aerobic/ endurance sports.

3. The peak of injuries was at age 15 where almost $9 \%$ of all injuries occurred. This seems a poor comment on the supervision of adolescent sport and should stimulate further research interest into the aetiology of sports injury in this age group.

\section{REFERENCES}

Adams, I. D., 1980 “Sports injury and osteoarthritis". The Practitioner 224: 61-64.

Butler, T., 1980 "Sports injury clinies Bristol University". Medisport 2: 18.

Compton, B. and Tubbs, N., 1977 "A survey of sports injuries in Birmingham". Brit.J.Sports Med. 11: $12-14$.

Cyriax, J., 1975 "Sports injury clinics”. Brit.Med.J. 2: 488.

Davies, J. E. and Gibson, T., 1978 "Injuries in Rugby Union footbali". Brit.Med.J. 2: 1759-1760.

Devereaux, M. D. and Lachmann, S. M., 1983 "Athletes attending a sports injury clinic; a review". Brit.J.Sports Med. 17: $137-142$.

Galasko, C. S. B., Menon, T. J., Banks, A. J., Morris, M. A., Bourne, M. S. and Bentley, S., 1982 "University of Manchester sports injury clinic". Brit.J.Sports Med. 16 (1): 23-26.

Mowat, C., 1981 "Soft tissue injury clinic: Oxford". Medisport 3: 38-39.

Muckle, D. S. and Shepherdson, H., 1975. Football Fitness and Injuries. Pelham, London.

Newman, P. H., Thomson, J. P. S., Barnes, J. M. and Moore, T. M. C., 1969 "A clinic for athletic injuries". Proc. Roy. Soc.Med. 62: 939.

Orava, S. and Puranen, J., 1978 "Exertion injuries in adolescent athletes". Brit.J.Sports Med. 12: 4-10.

Personal Communication. Meteorological Office, Exeter Airport, Statistics July-Dec. incl. 1982.

Silver, J. R., 1984 "Injuries of the spine sustained in Rugby". Brit.Med.J. 288: 37-43.

Sleet, R. and Donnan, S., 1979 "The view of one hospital Accident and Emergency Department". Medisport 1: 26-27.

Sperryn, P. N. and Williams, J. G. P., 1975 "Why sports injuries clinics”. Brit.Med.J. 2: 365. 
Tanner, J. M., Whitehouse, L. H. and Takaishim, 1966 "Standards from birth to maturity for height, weight, height velocity, and weight velocity for British children". 1965. Archives of Diseases in Childhood. 41, 454;613.

Weightman, D. and Browne, R. C., 1974 "Injuries in Association and Rugby football". Brit.J.Sports Med. 8: $183-187$.

Williams, J. G. P., 1981 “Overuse injuries in children". Medisport 3: 122-125.

Williams, J. G. P., 1973. Injury in Sport. Bayer.

\section{BOOK REVIEW}

Title: SPORT BIBLIOGRAPHY - 'AQUATIC, OUTDOOR AND WINTER SPORTS'

Editors: I. Draayer, G. Chiasson, L. Replansky and L. Wheeler

Publisher: Sport Information Resource Centre, Ottawa, Canada Price: $\$ 25.008$ Volume set $\$ 175 \quad 282$ pages Index No figs. Soft cover

This book is Volume 1 of a series of eight covering publications mostly in English and French in the fields of Aquatic Sport, Outdoor Activities and Winter Sports. Other volumes in the series are devoted to ball games (Vol. 2), Combat sports and racquet games (Vol. 3), Aeronautical, vehicular and equestrian sport (Vol. 4), Training (Vol. 5), Olympic and other major events (Vol. 6), Administration (Vol. 7) and finally Anthropometry, Physiology and Medicine (Vol. 8).

To write a review of such a bibliography is as difficult as to review a telephone directory or a dictionary. A comprehensive set of references is given for all published work that could be located by the Sport Information Resource Centre in both of Canada's main languages between 1974 and 1980, with a less complete collection prior to 1974. In Volume One there are some nine thousand citations, of books, of periodical articles and of theses available on microfilm of otherwise retrievable. Besides the names of the author(s) and title of the book or paper, the language is specified, anब also the academic level, whether advanced research level, intermediate, or basic easy reading. The citations are arranged in alphabetical order of subjects, and the number in each group varies; for example, under 'Aquatic Sports - General' there are eleven entries for both 'Injuries and Accidents' and 'Medicine' but only one, in German, for 'Physiology'. Under the section on 'Body Surfing' there are only two entries, one at Intermediate level and one at Basic.

The topics also range widely; in the section on 'Canoeing' there are fifty articles quoted on 'Equipment', two on 'Careers' and setting up a business, four on 'Injuries' and six on 'Medicine'. 'Boating Sports' and 'Ice Sports' are included as 'Aquatic Sports', these subjects taking up 190 of the total of 267 pages of the main text. The 30 pages on 'Outdoor Activities' covers camping and hiking, including such activities for the disabled, 'Climbing' with thirteen entries under 'Injury' and 115 under 'Medicine', a vital bibliography for doctors on high altitude or polar expeditions. The forty pages on 'Winter Sports' cover skiing, with large sections on 'Injuries' (68 entries) and 147 on 'Medicine'.

I am sure I shall find the volume I have been sent invaluable for checking references, and know that the complete set could be an essential purchase for any library serving readers in sport, sports medicine, exercise physiology and physical education and recreation in general.

H. E. Robson 